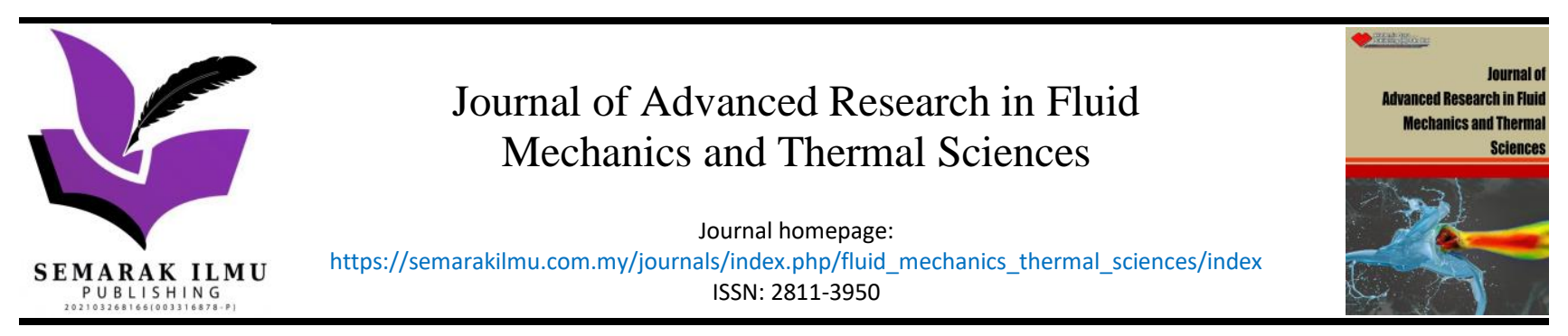

\title{
Air-Flow Simulation in Child Respirator for Covid-19 Personal Protection Equipment Using Bamboo-Based Activated Carbon Filter
}

\author{
I Made Putra Arya Winata ${ }^{1}$, Putu Emilia Dewi², Putu Brahmanda Sudarsana ${ }^{1}$, Made Sucipta ${ }^{1, *}$ \\ Department of Mechanical Engineering, Udayana University, Denpasar, Indonesia \\ 2 Department of Medical Science, Faculty of Health Science and Medicine, Udayana University, Denpasar Indonesia
}

ARTICLE INFO

Article history:

Received 26 September 2021

Received in revised form 9 December 2021

Accepted 15 December 2021

Available online 19 January 2022

\section{Keywords:}

Air-flow simulation; bamboo-based carbon filter; child respirator; Covid-19; flow trajectories

\section{ABSTRACT}

The use of personal protective equipment during the Covid-19 pandemic may inhibit the social interaction and learning process of children. A child respirator that is suitable for children's growth and development has been developed. Its designing process was done by computer-aided design and validated by computational fluid dynamics simulation. The device consists of inhale and exhale system, face cover, and headband. Various air filter is embedded in the inhale system, such as prefilter, HEPA filter, and bamboo-based activated carbon filter. Meanwhile, the exhale system contains HEPA filter only. Preliminary air-flow simulation in various breathing scenarios has been conducted with a result of velocity range from $0.067 \mathrm{~m} / \mathrm{s}$ up to $1.190 \mathrm{~m} / \mathrm{s}$ inside the respirator with a 0.47 $\mathrm{Pa}$ pressure difference. Flow trajectories analysis shows that the exhaled air is successfully directed to the exhale and inhale system and thus filtration can occur rapidly. These analyses also indicate that the device's average airflow velocity meets the standard requirements for child breathing apparatus. Child respirators using the bamboo-based activated carbon filter can be a great solution in implementing health protocols for children during the Covid-19 pandemic.

\section{Introduction}

The Covid-19 pandemic has become a global problem. The disease has caused by the SARS-CoV2 virus, which transmits through droplets. Covid-19 infection can occur in various age groups, including children [1]. The child's immune system has not developed well yet, so children are vulnerable to Covid-19 infection. Children need more frequent close contact with adults. It will increase the risk of transmission of Covid-19 from adults to children considering that SARS-Cov-2 transmits through droplets that spread in close contact (less than 1 meter). In addition, most of the children infected with SARS-Cov-2 do not show any symptoms, so they are at risk of becoming agents of spreading the virus in their environment [2]. In a younger child, the disease can cause fatal complications such as multisystem inflammatory syndrome in children, a collection of symptoms of

\footnotetext{
* Corresponding author.

E-mail address: m.sucipta@unud.ac.id

https://doi.org/10.37934/arfmts.91.1.8391
} 
inflammation in various systems of the child's body (MIS-C) [3, 4]. Therefore, personal protective equipment becomes a point to prevent Covid-19 infection in children and its complications.

Ironically, the children's health protocols may affect the social development and learning process of children. Children are not free to explore and get to know their environment $[5,6]$. In addition, it can hinder children's motor development, considering that the commercialized masks cannot support various physical activities that require extra air circulation. The mask's design that muffles sound and covers the mouth movements or expressions of the interlocutor hinders the child's learning process to new words, especially for those with special needs $[7,8]$. The use of conventional masks and face shields in the long term can also irritate so that children become less comfortable in their activities and tend to touch their faces more often [6].

Unfortunately, there has not been much development of Covid-19 prevention protocols used in children. Apart from that, some breakthroughs in providing respiratory support facilities for children have been commercialized, such as respiratory gas masks used on the battlefield [9]. However, the design of this tool still limits the child's space for movement. Respirators with a more portable design for medical personnel also have been produced. However, the devices only filter particles above 0.3 microns, whereas viruses and most other pathogens are approximately 0.1 microns in size [10]. The most advanced respirators combine various air filtration and disinfection components in a portable device that supports comfort. However, these advanced air filtration respirators have a high price, so they cannot be reached by all people [11].

Therefore, a child respirator that is suitable for children's growth and development is required. Bamboo activated carbon has good particle adsorption capacity and is also an easy-to-find air filtration material. This material can adsorb various nano-sized particles that will protect children from exposure to viruses and other pathogens because of its less than 0.1 microns pore size. In addition, bamboos are also easily obtained in Asia [12]. Air-flow simulations were done to obtain optimum results. By then, any pathogen that potentially harms the user was expected to be blocked in the way to the respiratory system. A preliminary simulation is also necessary to determine the direction of air flow in a normal breathing scenario and also to predict the data parameters which potentially affect the comfort when the respirator is used.

\section{Methods}

\subsection{Design}

The study of respirators conducted by Chen in 2014 along with Khoo's in 2020 development provides a deeper understanding of how respirators should work [13, 14]. The design of the respirator that has been widely developed considers aspects of comfort and safety when used in respiration. Of course, the optimization of the development of the respirator is carried out in such a way that the user can easily adapt properly without a respirator.

To specified, a review can be made of the face size and shape. This is one of the keys to optimizing the comfort aspect. Therefore, a children's anthropometry generalization review was used as a consideration in the design [15]. The face category represented in the data is a set of various face dimensions of children in the age groups of 0 to 7 years. This condition is following the target market for the bamboo-based activated carbon filter child respirator. The design process refers to research data that has been collected through literature studies and surveys of component availability in the market. The design of the respirator was developed based on anthropometric data of children and direct measurement of several children [15]. The design process utilized 3D computer-aided-design (CAD) software SOLIDWORKS ${ }^{\circledR} 2021$. 


\subsection{Simulation}

To evaluate the design fitness and air-flow trajectories, a preliminary simulation study was conducted using SOLIDWORKS ${ }^{\circledR} 2021$ Flow Simulation. The computational domain of the flow simulation was determined according to the design of the respirator under usage conditions. The boundary condition is defined in the mouth and nose section with inhale volume flow as shown in Table 1. This condition is calculated according to the respiratory volume and child's respiratory rate data as several breathing scenarios for children. The filters were defined as a porous medium with a material approach of 1-inch nominal MERV 15 for pre-filter and HEPA filter, while bamboo charcoal activated carbon filter was defined as UFM-100 White Polyester in the simulation process. SOLIDWORKS ${ }^{\circledR} 2021$ Flow Simulation adapts a Cartesian-based meshing method, which is defined as a set of cuboids (rectangular cells) oriented along the Cartesian coordinates [16]. The meshing was divided into global mesh and local mesh. Global mesh was set to automatic with level 5 initial mesh. The local mesh, located in inlet boundary conditions, inhale, and exhale system, was set with level 4 of cells refinement. The SOLIDWORKS ${ }^{\circledR}$ Flow Simulation solves the problem defined using the governing equations, which is the Navier-Stokes equations. The Navier-Stokes equations are the formulations of mass, momentum, and energy conservation laws.

Mass conservation laws

$\frac{\partial \rho}{\partial t}+\frac{\partial\left(\rho u_{i}\right)}{\partial x_{i}}=0$

Momentum conservation laws

$\frac{\partial\left(\rho u_{i}\right)}{\partial t}+\frac{\partial}{\partial x_{j}}\left(\rho u_{i} u_{j}\right)+\frac{\partial P}{\partial x_{i}}=\frac{\partial}{\partial x_{j}}\left(\tau_{i j}+\tau_{i j}^{R}\right)+S_{i}$

Energy conservation laws

$$
\begin{aligned}
& \frac{\partial \rho H}{\partial t}+\frac{\partial \rho u_{i} H}{\partial x_{i}}=\frac{\partial}{\partial x_{i}}\left(u_{j}\left(\tau_{i j}+\tau_{i j}^{R}\right)+q_{i}\right)+\frac{\partial p}{\partial t}-\tau_{i j}^{R} \frac{\partial u_{i}}{\partial x_{j}}+\rho \varepsilon+S_{i} u_{i}+Q_{H} \\
& H=h+\frac{u^{2}}{2}
\end{aligned}
$$

The flow analysis in this research is considered to be turbulent, with an approach to the transport equations for turbulent kinetic energy and its dissipation rate. The turbulent parameters are set to the $k-\varepsilon$ model, with the turbulence conservation laws as follow:

$$
\begin{aligned}
& \frac{\partial \rho k}{\partial t}+\frac{\partial \rho k u_{i}}{\partial x_{i}}=\frac{\partial}{\partial x_{i}}\left(\left(\mu+\frac{\mu_{t}}{\sigma_{k}}\right) \frac{\partial k}{\partial x_{i}}\right)+\tau_{i j}^{R} \frac{\partial u_{i}}{\partial x_{j}}-\rho \varepsilon+\mu_{t} P_{B} \\
& \frac{\partial \rho \varepsilon}{\partial t}+\frac{\partial \rho \varepsilon u_{i}}{\partial x_{i}}=\frac{\partial}{\partial x_{i}}\left(\left(\mu+\frac{\mu_{t}}{\sigma_{\varepsilon}}\right) \frac{\partial \varepsilon}{\partial x_{i}}\right)+C_{\varepsilon 1} \frac{\varepsilon}{k}\left(f_{1} \tau_{i j}^{R} \frac{\partial u_{i}}{\partial x_{j}}+C_{B} \mu_{t} P_{B}\right)-f_{2} C_{\varepsilon 2} \frac{\rho \varepsilon^{2}}{k} \\
& \tau_{i j}=\mu s_{i j}, \quad \tau_{i j}^{R}=\mu_{t} s_{i j}-\frac{2}{3} \rho k \delta_{i j}, \quad s_{i j}=\frac{\partial u_{i}}{\partial x_{j}}+\frac{\partial u_{j}}{\partial x_{i}}+\frac{2}{3} \delta_{i j} \frac{\partial u_{k}}{\partial x_{k}},
\end{aligned}
$$




$$
P_{B}=-\frac{g_{i}}{\sigma_{B}} \frac{1}{\rho} \frac{\partial \rho}{\partial x_{i}}
$$

With determined parameters as follow:

$$
\begin{gathered}
C_{\mu}=0.09, \quad C_{\varepsilon 1}=1.44, \quad C_{\varepsilon 2}=1.92, \quad \sigma_{k}=1, \quad \sigma_{\varepsilon}=1.3, \quad \sigma_{B}=0.9, \\
C_{B}=1 \text { if } P_{B}>0, \quad C_{B}=0 \text { if } P_{B}<0,
\end{gathered}
$$

The turbulent viscosity is determined from:

$$
\mu_{t}=f_{\mu} \frac{C_{\mu} \rho k^{2}}{\varepsilon}
$$

\section{Results and Discussion}

\subsection{Respirator Design}

The child respirator consists of four main components that will bring optimalization due to comfort and protection. The four main components as told, such as inhale and exhale systems, face cover, and headband (see Figure 1). The inhale and exhale system consisting of air filters supports children's respiration, inhalation and exhalation. The bamboo-based activated carbon and HEPA filter are also embedded in the inhale system to provide better hazardous particle adsorption. Meanwhile, the exhale system consists of HEPA filter only. In this way, the filter would give better protection as it is being used. The main face cover is made of acrylic and surrounded by silicon rubber as a better way to contact the respirator to the child face. In addition to provide face fitness, the face cover is designed anthropometrically fit children while still serving their visual acuity and communication needs. As the last components to mention, the headband, made of rubber materials, helps tighten the respirator to children's head when it is being used.

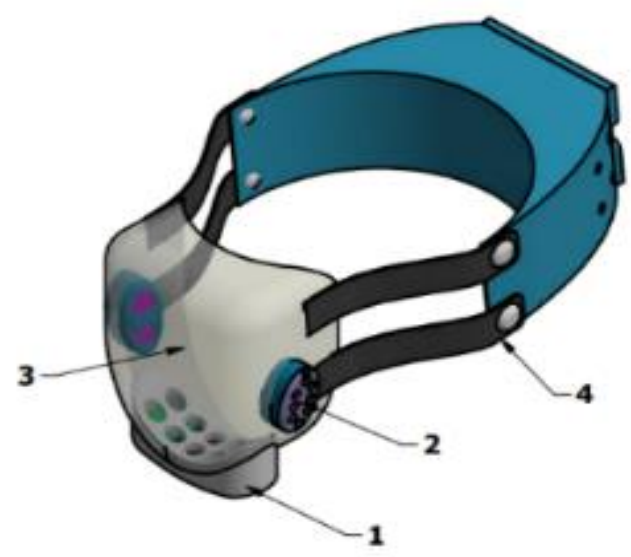

Fig. 1. Child respirator using bamboobased activated carbon filter consists of (1) inhale system, (2) exhale system, (3) face cover, and (4) headband. 


\subsection{Air-flow Simulation}

As the design was mentioned, breathing scenario analysis of the respirator has been conducted using SOLIDWORKS 2021 Flow Simulation. The study obtained a visualization of the flow trajectories in several user's activities and conditions: 1) normal breathing, 2) in aerobic activities, 3) bradypnea condition, and 4) tachypnea condition. The respiratory volume, respiratory rate, and air-flow rate of each variation (see Table 1) were obtained from Jones' study in 1995 along with an update from Hancox and Rasmussen in 2017 [17, 18].

Furthermore, each of those activities and conditions adapted to the inhalation and exhalation process. The inhale simulation was done by decreasing the pressure in the nose and mouth area, so air enters only through the inlet. Meanwhile, the exhale simulation was done by increasing the pressure on the nose and mouth area. It causes the air to come out through the exhale and inhale system.

\subsubsection{Normal breathing}

The respiratory volume and rate in normal breathing condition was measured in resting condition. The trajectory flow for inhale and exhale simulation respectively shown in Figure 2 and Figure 3. In this analysis, the inhalation simulation results give an average velocity of $0.189 \mathrm{~m} / \mathrm{s}$. Meanwhile, the exhale simulation gives an average velocity of $0.149 \mathrm{~m} / \mathrm{s}$ at the inlet and 0.102 $\mathrm{m} / \mathrm{s}$ at the outlet.

\section{Table 1}

Respiratory volume, respiratory rate, and air-flow rate due to activities and conditions variation in children

\begin{tabular}{llll}
\hline & $\begin{array}{l}\text { Respiratory } \\
\text { Volume }(\mathrm{mL})\end{array}$ & $\begin{array}{l}\text { Respiratory } \\
\text { Rate }\left(\mathrm{bpm}^{\mathrm{a}}\right)^{\mathrm{b}}\end{array}$ & $\begin{array}{l}\text { Air-flow Rate } \\
\left(\mathrm{m}^{3} / \mathrm{s}\right)\end{array}$ \\
\hline Normal breathing & 500 & 16 & $1.33 \times 10^{-4}$ \\
Aerobic activities & 1,300 & 40 & $8.67 \times 10^{-4}$ \\
Bradypnea condition $^{\mathrm{c}}$ & 500 & 10 & $8.33 \times 10^{-4}$ \\
Tachypnea condition $^{\mathrm{d}}$ & 500 & 30 & $2.5 \times 10^{-4}$ \\
\hline${ }^{\text {a }}$ Breath per minute & & \\
${ }^{\mathrm{b}}$ the respiratory rate data represented the most clinically important measure of each condition [17] \\
${ }^{\mathrm{c}}$ Respiratory rate fall below 12 bpm \\
${ }^{d}$ Respiratory rate raised greater than $20 \mathrm{bpm}$
\end{tabular}

The inhale simulation shows that the air moves to the nose and mouth inlet, circulating inside the face cover before exiting from the exhale and inhale system. This airflow will support the air filtration performance. All air that passes through the respirator is ensured to flow through a combination of filters. The mechanism will reduce harmful air particles, both inhaled by the children and exhaled into the environment. The maximum flow velocity within the range of $0.430 \mathrm{~m} / \mathrm{s}$ up to 0.592 $\mathrm{m} / \mathrm{s}$ occurs in the outlet region of the mouth and nose. As the air-flow exits the inhale and exhale system, the velocity of the flow reduces drastically. Due to a circulation phenomenon inside the respirator, a pressure difference occurs of about $0.47 \mathrm{~Pa}$. 


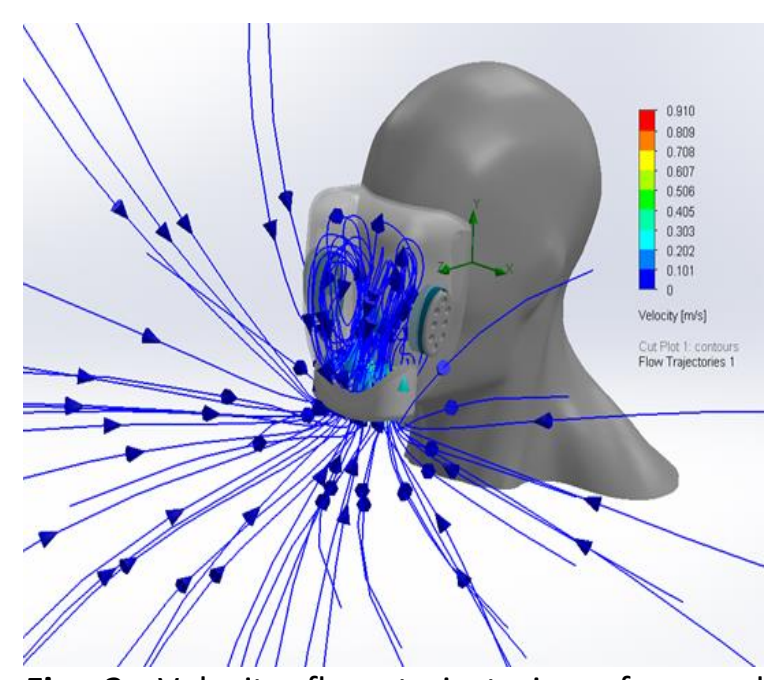

Fig. 2. Velocity flow trajectories of normal breathing inhalation scenario in the child respirator

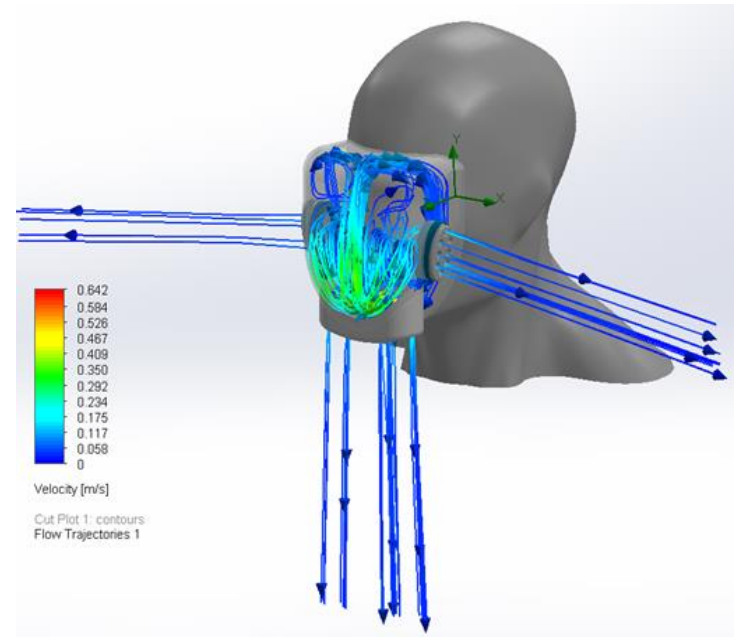

Fig. 3. Velocity flow trajectories of normal breathing exhalation scenario in the child respirator

\subsubsection{Aerobic activities}

The data in aerobic activities was obtained in a body endurance exercise. The trajectory flow for inhale simulation gives an average velocity of $1.190 \mathrm{~m} / \mathrm{s}$ at the inlet (see Figure 4). Meanwhile, the average velocity of $1.164 \mathrm{~m} / \mathrm{s}$ at the inlet and $0.583 \mathrm{~m} / \mathrm{s}$ at the outlet were shown in exhale simulation (see Figure 5).

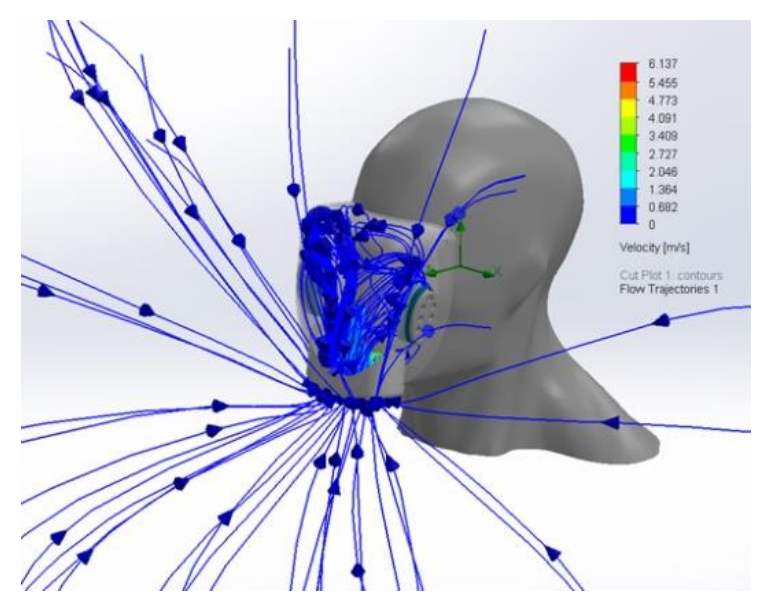

Fig. 4. Velocity flow trajectories of aerobic exercise inhalation scenario in the child respirator

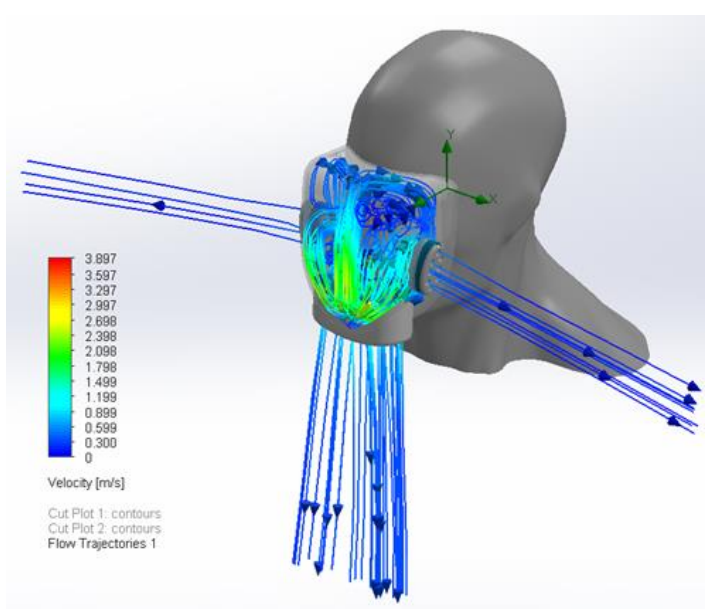

Fig. 5. Velocity flow trajectories of aerobic exercise exhalation scenario in the child respirator

\subsubsection{Bradypnea condition}

When the respiratory rate falls below normal as in bradypnea condition, the average velocity in inhale simulation was $0.118 \mathrm{~m} / \mathrm{s}$ across the inlet (see Figure 6). In the exhale simulation, the air-flow exits the device in average velocity of $0.088 \mathrm{~m} / \mathrm{s}$ at the inlet and $0.067 \mathrm{~m} / \mathrm{s}$ at the outlet (see Figure 7). 


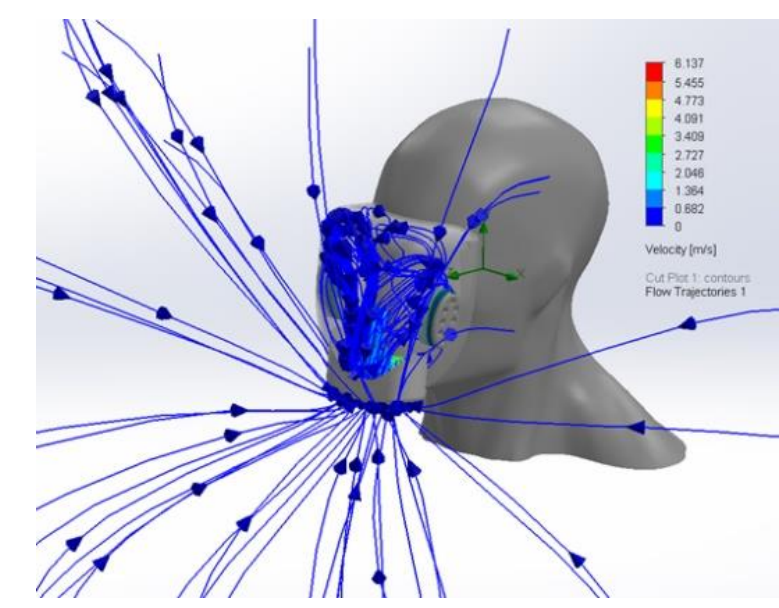

Fig. 6. Velocity flow trajectories of bradypnea inhalation scenario in the child respirator

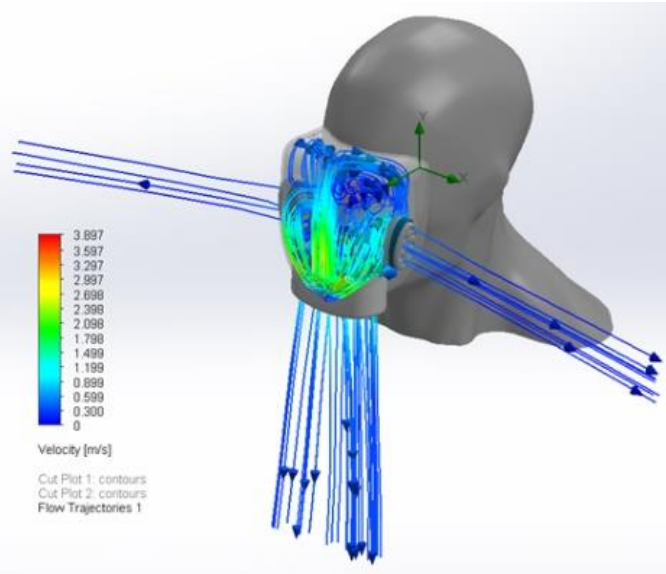

Fig. 7. Velocity flow trajectories of bradypnea exhalation scenario in the child respirator

\subsubsection{Tachypnea condition}

In high respiratory rate condition, the air-flow entrances the device in average velocity of 0.350 $\mathrm{m} / \mathrm{s}$ through the inhale system (see Figure 8). On the other side, the trajectory flow for exhalation shows an average velocity of $0.302 \mathrm{~m} / \mathrm{s}$ across the inlet and $0.179 \mathrm{~m} / \mathrm{s}$ across the outlet (see Figure 9).

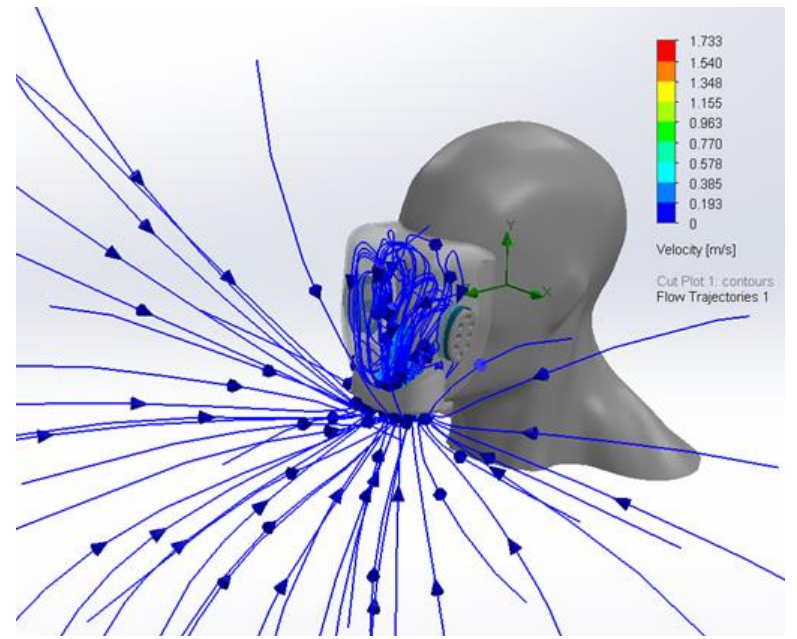

Fig. 8. Velocity flow trajectories of tachypnea inhalation scenario in the child respirator

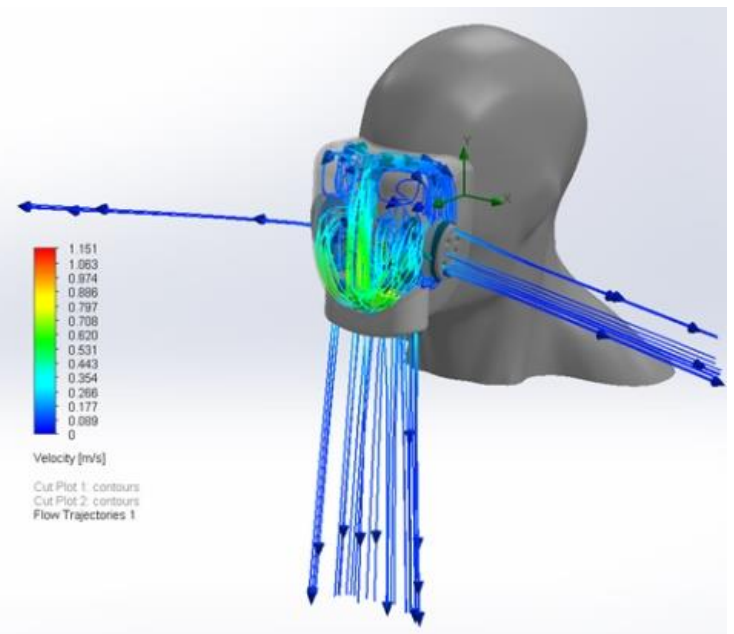

Fig. 9. Velocity flow trajectories of tachypnea exhalation scenario in the child respirator

All of the data in Figure 10, indicate that the respirator design meets the standard requirements for child breathing apparatus. The device's average airflow velocity shows a lower value than the upper limit of air velocity in the child respiration cycle. Device's average air during inhalation range from $0.118 \mathrm{~m} / \mathrm{s}$ up to $1.190 \mathrm{~m} / \mathrm{s}$. Meanwhile, the maximum inhaled air velocities in children are $1.820 \mathrm{~m} / \mathrm{s}$ [19].

The similar thing is also obtained in the exhale simulation. The device's average airflow velocity ranges from $0.067 \mathrm{~m} / \mathrm{s}$ to $0.583 \mathrm{~m} / \mathrm{s}$ at the outlet part. It is below the maximum exhaled air velocities in child standard, $1.120 \mathrm{~m} / \mathrm{s}$ [19]. Meanwhile at the inlet part, the device's average airflow velocity was $0.088 \mathrm{~m} / \mathrm{s}$ to $1.164 \mathrm{~m} / \mathrm{s}$. This part would not affect much because its function is not mainly as 
an exhalation system. Therefore, the child respirator design will not interfere children's activities comfort.

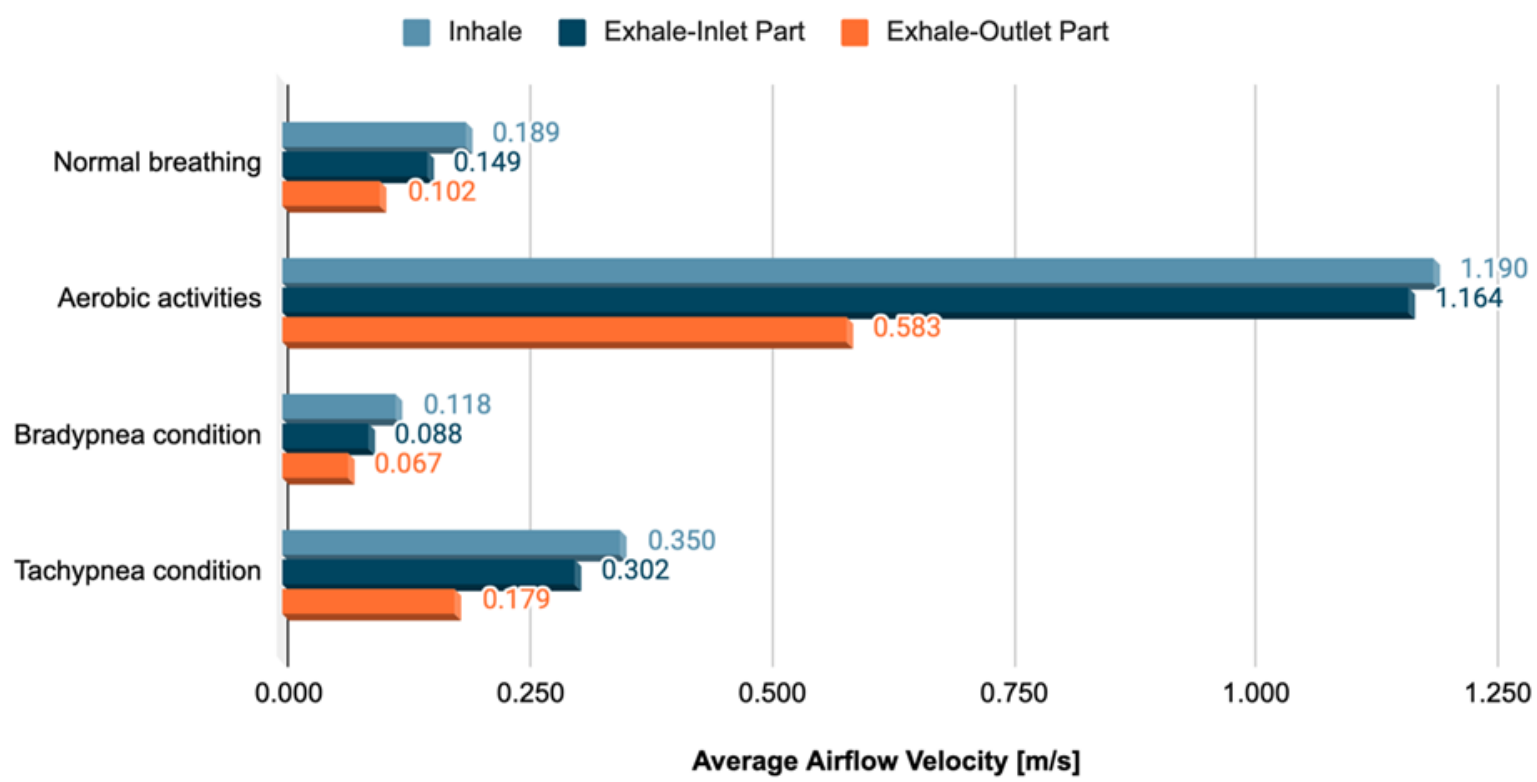

Fig. 10. Average airflow velocity on inhale and exhale simulation conducted in various activities and conditions

\section{Conclusions}

Bamboo-based activated carbon filters in child respirators may become a great low-cost child personal protective equipment alternative. Trajectories analysis shows that the air flows successfully through the inhale system. It ensures that the air inhaled by children completely passes through the inlet and outlet. For instance, it will circulate through a combination of bamboo-based activated carbon filters. Meanwhile, the air exhaled by children will go through the inlet and outlet at the same time. The air that comes out through the respirator will also be filtered. This mechanism can reduce particle residues that are carried through the breathing air to the environment. The respirator's design has a good direction of air-flow in a breathing scenario, which means it will provide child's comfort when used.

\section{Acknowledgements}

This work was funded by the Directorate of Learning and Student Affairs in General Directorate of Higher Education at Ministry of Education, Culture, Research, and Technology Republic of Indonesia, through "Program Kreativitas Mahasiswa Karsa Cipta" with the contract number 015/E2/PPK/SPPK/PKM/2021 and supported by Faculty of Engineering Udayana University and Faculty of Health Science and Medicine Udayana University.

\section{References}

[1] World Health Organization. "Anjuran mengenai penggunaan masker dalam konteks COVID-19." World Health Organization, April (2020): 1-6.

[2] Zhu, Li, Jian Wang, Rui Huang, Longgen Liu, Haiyan Zhao, Chao Wu, and Chuanwu Zhu. "Clinical characteristics of a case series of children with coronavirus disease 2019." Pediatric pulmonology 55, no. 6 (2020): 1430-1432. https://doi.org/10.1002/ppul.24767

[3] Dewi, Rismala, Nastiti Kaswandani, Mulya Rahma Karyanti, Darmawan Budi Setyant, Antonius Hocky Pudjiadi, Aryono Hendarto, Mulyadi M. Djer et al. "Mortality in children with COVID-19: Lessons learned from a tertiary 
referral hospital in Indonesia." International Journal of Infectious Diseases (2021). https://doi.org/10.1016/j.ijid.2021.04.019

[4] Nakra, Natasha A., Dean A. Blumberg, Angel Herrera-Guerra, and Satyan Lakshminrusimha. "Multi-system inflammatory syndrome in children (MIS-C) following SARS-CoV-2 infection: review of clinical presentation, hypothetical pathogenesis, and proposed management." Children 7, no. 7 (2020): 69. https://doi.org/10.3390/children7070069

[5] Ahad, Nor Aishah, Friday Zinzendoff Okwonu, and Pang Yik Siong. "COVID-19 Outbreak in Malaysia: Investigation on Fatality Cases." Journal of Advanced Research in Applied Sciences and Engineering Technology 20, no. 1 (2020): 1-10. https://doi.org/10.37934/araset.20.1.110

[6] World Health Organization. Advice on the use of masks in the context of COVID-19: interim guidance, 5 June 2020. No. WHO/2019-nCoV/IPC_Masks/2020.4. World Health Organization, 2020.

[7] Eberhart, Martin, Stefan Orthaber, and Reinhold Kerbl. "The impact of face masks on children-A mini review." Acta Paediatrica 110, no. 6 (2021): 1778-1783. https://doi.org/10.1111/apa.15784

[8] Spitzer, Manfred. "Masked education? The benefits and burdens of wearing face masks in schools during the current Corona pandemic." Trends in neuroscience and education 20 (2020): 100138. https://doi.org/10.1016/i.tine.2020.100138

[9] Impertech 2019 Powered Air Purifying Respirator for Infant \& Child.

[10] Elkington, Paul, Alexander Dickinson, Mark Mavrogordato, Daniel Spencer, Richard Gillams, Antonio De Grazia, Sebastian Rosini et al. "A personal respirator specification for healthcare professionals treating COVID-19 (PeRSo)." EngrXiv (2020). https://doi.org/10.31224/osf.io/rvcs3

[11] Leaf Healthcare 2020 Leaf PRO.

[12] Negara, Dewa Ngakan Ketut Putra, Tjokorda Gde Tirta Nindhia, I. Wayan Surata, and Made Sucipta. "Development and application of bamboo activated carbons and their potency as adsorbent material for adsorbed natural gas (ANG); an overview." In Key Engineering Materials, vol. 705, pp. 126-130. Trans Tech Publications Ltd, 2016. https://doi.org/10.4028/www.scientific.net/KEM.705.126

[13] Chen, Yumiao, Jianping Wang, and Zhongliang Yang. "The human factors/ergonomics studies for respirators: a review and future work." International Journal of Clothing Science and Technology (2015). https://doi.org/10.1108/IJCST-06-2014-0077

[14] Khoo, Deborah, Ching-Chiuan Yen, Wai Tung Chow, Pravar Jain, Ne-Hooi Will Loh, Wei Wei Teo, and Calvin Koh. "Ultra-portable low-cost improvised powered air-purifying respirator: feasibility study." BJA: British Journal of Anaesthesia 125, no. 2 (2020): e264. https://doi.org/10.1016/i.bja.2020.04.082

[15] Goto, Lyè, Wonsup Lee, Johan FM Molenbroek, Annoesjka J. Cabo, and Richard HM Goossens. "Traditional and 3D scan extracted measurements of the heads and faces of Dutch children." International Journal of Industrial Ergonomics 73 (2019): 102828. https://doi.org/10.1016/j.ergon.2019.102828

[16] Sobachkin, A., and G. Dumnov. "Numerical basis of CAD-embedded CFD." In NAFEMS World Congress, pp. 9-12. 2013.

[17] Everley, Tones H. "The vital capacity of children." Arch Dis Child 30 (1955): 445-445. https://doi.org/10.1136/adc.30.153.445

[18] Hancox, Robert J., and Finn Rasmussen. "Does physical fitness enhance lung function in children and young adults?." European Respiratory Journal 51, no. 2 (2018). https://doi.org/10.1183/13993003.01374-2017

[19] Tsega, Endalew Getnet. "Computational fluid dynamics modeling of respiratory airflow in tracheobronchial airways of infant, child, and adult." Computational and mathematical methods in medicine 2018 (2018). https://doi.org/10.1155/2018/9603451 